\title{
Angiogenesis and lymphangiogenesis in thyroid proliferative lesions: relationship to type and tumour behaviour
}

\author{
N Garcia de la Torre, I Buley², J A H Wass ${ }^{1}$ and H E Turner ${ }^{1}$
}

\author{
Servicio de Endocrinología y Nutrición, Hospital Clínico San Carlos, Profesor Martín Lagos s/n, 28040 Madrid, Spain \\ ${ }^{1}$ Department of Endocrinology, The Oxford Centre for Diabetes, Endocrinology and Metabolism, Churchill Hospital, Old Road, \\ Headington, Oxford OX3 7LJ, UK \\ ${ }^{2}$ Department of Histopathology, Torbay General Hospital, Lawes Bridge, Torquay, Devon TQ2 7AA, UK \\ (Requests for offprints should be addressed to H E Turner; Email: helen.turner@orh.nhs.uk)
}

\begin{abstract}
The role of angiogenesis and lymphangiogenesis in thyroid cancer pathogenesis has not been elucidated. Patterns for tumour behaviour and metastasic spread vary according to tumour type and whether differences in the angiogenic or lymphangiogenic phenotype influence the route for tumour metastases or determine a more aggressive behaviour has not been fully explored. The angiogenic and lymphangiogenic phenotypes of a large cohort of thyroid proliferative lesions ( $n=191)$ were studied. Using immunohistochemistry for CD34, lymphatic vessel endothelial receptor-1 (LYVE-1) (specific markers for vascular and lymphatic endothelium respectively), vascular endothelial growth factor (VEGF-A), VEGF-C and fibroblast growth factor-2 (FGF-2), this study analyses microvascular density (MVD), lymphatic vascular density (LVD), and expression of angiogenic and lymphangiogenic factors in normal thyroid (NT; $n=19)$, multinodular goitre $(n=$ $25)$, toxic multinodular goitre $(n=8)$, Graves' hyperplasia $(n=22)$, follicular adenoma $(n=54)$, papillary carcinoma (PC; $n=27$ ), incidental papillary microcarcinoma (PMC; $n=8)$, follicular carcinoma (FC; $n=20$ ) and medullary carcinoma (MC; $n=8)$. MVD was decreased in proliferative lesions, benign and malignant, compared with NT $(P<0.0001)$. In contrast, VEGF-A expression was increased in thyroid carcinomas (PC, FC and $\mathrm{MC}$ ) when compared with $\mathrm{PMC}$, benign lesions and NT $(P<0.0001)$. LVD was higher in PC and PMC $(P=0.001)$, and VEGF-C expression was increased in PC $(P<0.0001)$. Despite higher LVD and increased expression of VEGF-A and VEGF-C in thyroid cancers, these markers were not related to poor prognosis in terms of tumour size, multifocality and/or presence of lymphatic or distant metastases. In conclusion, angiogenesis is reduced in thyroid proliferative lesions compared with NT tissue. However, VEGF-A expression is upregulated in thyroid cancers. Lymphangiogenesis and VEGF-C expression are increased in thyroid tumours prone to lymphatic metastases. This may be an important mechanism underlying the differences in metastatic behaviour between papillary and follicular thyroid cancer.
\end{abstract}

Endocrine-Related Cancer (2006) 13 931-944

\section{Introduction}

Angiogenesis, the formation of new blood vessels from pre-existing vasculature, is known to play an important role in the development, growth and metastases of carcinomas (Folkman 1989). The search for potential stimuli for angiogenesis has yielded numerous candidates including vascular endothelial growth factor A (VEGF-A), fibroblast growth factor-2 (FGF-2), transforming growth factor $\alpha$ (TGF- $\alpha$ ), TGF- $\beta$, hepatocyte growth factor, tumour necrosis factor $\alpha$, interleukin 8
(IL-8) and the angiopoietins (Yancopoulos et al. 2000). VEGF-A was characterised as a heparin binding growth factor displaying high specificity for endothelial cells, which plays a pivotal role in both physiological and pathological angiogenesis through the increase in proliferation and migration of endothelial cells (Ferrara \& Bunting 1996) and permeabilisation of blood vessels by inducing pores or fenestrations in the endothelium (Esser et al. 1998). The FGF-2 is a member of a large family of structurally 
related proteins that affect the growth, differentiation, migration and survival of a wide variety of cell types. One of the best characterised activities of FGF-2 is the ability to stimulate proliferation of endothelial cells (Vlodavsky et al. 1987).

In contrast to the process of angiogenesis, the molecular mechanisms regulating the growth and function of lymphatic vessels are poorly understood. Using a novel marker for lymphatic endothelium, LYVE-1, Skobe et al. (2001) identified VEGF-C as the molecular link between tumour lymphangiogenesis and metastases in an animal model. VEGF-C has been shown to be a potent lymphangiogenic factor, which induces proliferation of lymphatic endothelial cells in vitro (Oh et al. 1997) and lymphatic hyperplasia (Hy) in vivo (Jeltsch et al. 1997). Several studies have now shown that human cancers that metastasise to lymph nodes are associated with upregulation of VEGF-C expression (reviewed in Nisato et al. 2003).

Thyroid cancer accounts for around $1 \%$ of all cases of malignant neoplasia and it is among the five most frequent cancers in the second, third and fourth decades of life. When compared with other malignancies, thyroid cancer has long-term survival rates, at least in the well-differentiated histotypes. However, some patients are at high risk for recurrent disease and these tumours can certainly metastasise and are occasionally fatal. However, reliable predictive factors determining aggressive tumour behaviour are lacking. Distinct molecular events occurring in hyperplastic and neoplastic thyroid disease have been studied extensively. Particular attention has focussed on the activation of several proto-oncogenes or growth factor receptors (braf, ras, ret, NTRK, met, gsp and TSH receptor), alterations in tumour suppressor genes ( $p 53$, $R b$ ), gene rearrangements and chromosomal translocations (ret/PTC, NTRK, Pax-8/PPAR- $\gamma$ ) and specific environmental factors (iodine deficiency, ionising radiations) (reviewed in Kim et al. 2003). However, the role of angiogenesis and lymphangiogenesis in thyroid cancer pathogenesis has not been clarified. Different carcinomas have different patterns for metastatic spread. For example, papillary thyroid carcinoma tends to metastasise to regional lymph nodes, whereas follicular thyroid carcinoma usually metastasises by a haematogenous rather than by a lymphatic route. On the other hand, incidental papillary microcarcinomas (PMCs) tend to remain small and further progression is uncommon. Other less common thyroid cancers such as medullary carcinoma (MC) and anaplastic carcinoma also frequently metastasise to lymph nodes (Rodriguez et al. 2000, Scollo et al. 2003). Whether differences in the angiogenic or lymphangiogenic phenotype can influence the route for tumour metastases or determine a more aggressive behaviour has not been fully explored.

The aims of this study were: (1) to analyse microvascular density (MVD) as a measure of angiogenesis using CD34 staining, which is a specific marker for detection of all vascular endothelial cells (mature and immature) and lymphatic vascular density (LVD) as a measure of lymphangiogenesis using LYVE-1 staining, which is a specific marker for detection of lymphatic vascular endothelial cells, in a large cohort of thyroid proliferative lesions compared with normal tissue; (2) to investigate the expression of the pro-angiogenic and lymphangiogenic factors VEGF-A, FGF-2 and VEGF-C in thyroid tissue; and (3) to assess whether MVD, LVD and expression of these angiogenic and lymphangiogenic factors correlates with aspects of tumour behaviour (tumour size, multifocality, lymph nodes metastases at thyroidectomy and distant metastases at diagnosis) in a large cohort of thyroid carcinomas.

\section{Material and methods}

\section{Tumour collection}

A database of carefully characterised thyroid proliferative lesions was created at the beginning of the project. Consecutive thyroid tissue samples from patients of both sexes and ages ranging from 15 to 93 years were obtained from January 1995 to August 2001 archival records of the Department of Histopathology, John Radcliffe Hospital, Oxford, UK, between January 1995 and August 2001. For each patient, information including the clinical and hormonal status at presentation, imaging studies, pathology reports, the result of the surgery and local and distant recurrence during follow-up was obtained from the clinical notes. Tumour size was determined from the final histology report on the surgical specimen. Multifocal disease was defined as two or more foci of thyroid cancer within the thyroid gland. Metastatic thyroid cancer noted prior to surgery, or at the time of surgery in regional lymph nodes, was considered present during diagnosis and not a recurrence. Recurrence was defined as the new development of thyroid cancer as documented by cytology, histology, radioiodine avid tissue on nuclear medicine scanning or typical appearance of metastatic thyroid cancer on non-nuclear medicine imaging. Recurrences in the neck (thyroid bed or regional lymph nodes) were considered local recurrences. A recurrence outside the neck (including the mediastinum) was considered distant metastases. The study 
was approved by the Oxfordshire Clinical Research Ethics Committee.

One hundred and ninety one samples were available for analysis. These included multinodular goitre (25), toxic multinodular goitre (TMNG) (8), diffuse Hy due to Graves' disease (22), follicular adenoma (FA) (54), papillary carcinoma (PC) (27), PMC (8), follicular carcinoma (FC) (20), MC (8) and normal thyroid (NT) tissue (19). Samples of NT tissue came from patients with a previous hemithyroidectomy for a thyroid nodule, subsequently diagnosed as thyroid carcinoma, where completion of the thyroidectomy was later performed and the pathological examination of the contralateral lobe showed NT tissue. The PC group included two tumours of size $7 \mathrm{~mm}$, which were diagnosed in both cases after fine needle aspiration of a cervical mass, which resulted in a metastatic lymph node. Both patients had total thyroidectomy and careful pathological examination of the whole gland revealed a single carcinoma focus. All the samples in the PMC group were incidentally found during surgery for benign thyroid conditions and were $<1 \mathrm{~cm}$ in diameter. Table 1 describes the characteristics of the cases with thyroid carcinoma.

\section{Immunohistochemistry}

Four-micron sections were mounted on X-Tra slides (Surgipath Europe Ltd, Peterborough, UK), dried for $2 \mathrm{~h}$ at $42{ }^{\circ} \mathrm{C}$, progressively dewaxed and rehydrated by immersion in xylene, alcohol and water. Sections for CD34 did not require pre-treatment. Slides to be stained with LYVE-1, VEGF-C and FGF-2 were pre-treated by microwave in DAKO Target Retrieval Solution (DAKO Ltd, Cambridgeshire, UK) for $20 \mathrm{~min}$. Slides for staining with VEGF-A were pre-treated by microwave in DAKO High pH Target Retrieval Solution (DAKO) for $20 \mathrm{~min}$. The horseradish peroxidase Envision System (DAKO) was used for all staining. Endogenous peroxidase activity was blocked using DAKO blocking reagent as per kit (DAKO). The primary antibodies were applied for 30 min at room temperature. For CD34 and VEGF-A staining, mouse monoclonal antibodies produced by Nuffield Department of Clinical Laboratory Sciences, University of Oxford, UK, were applied at a dilution of 1:100 and 1:2 respectively (Turley et al. 1998, Stewart et al. 2002). The mouse anti-LYVE-1 monoclonal antibody produced by the Institute of Molecular Medicine, John Radcliffe Hospital, Oxford, UK, was used at a dilution of 1:2 (Trojan et al. 2004). The rabbit anti-human polyclonal antibodies for FGF-2 and VEGFC (Biotechnology, Inc; Santa Cruz, CA, USA) were used at a dilution of 1:250 and 1:50 respectively. After two washes in Tris-buffered saline for CD34 and Trisbuffered saline with $0.01 \%$ tween for LYVE-1, VEGFA, VEGF-C and FGF-2, secondary antibody bound to horseradish peroxidase via a dextran backbone (DAKO) was applied as per kit for $30 \mathrm{~min}$ at room temperature, followed by two washes. Colour development was performed with metal-enhanced diaminobenzidine (DAKO) applied for $5 \mathrm{~min}$. The slides were lightly counterstained with hematoxylin (Sigma Diagnostics). Breast carcinoma sections were used as positive controls for CD34, VEGF-A and FGF-2 staining and tonsil sections were used as positive controls for LYVE-1 and VEGF-C staining. Negative controls were obtained by omitting the primary antibodies.

\section{Assessment of vascular and lymphatic density}

All scoring and interpretations of immunohistochemical results were made by one examiner (N G T) without prior knowledge of histological diagnosis or size. The Chalkley point technique was used for assessment of vascular and lymphatic densities (Fox et al. 1995). The three most dense vascular and lymphatic areas (known as hot spots) were determined at low magnification. A 25-point Chalkley eyepiece graticule (Graticules Ltd, Tonbridge, UK) was orientated so that the maximum number of points was on or within areas of highlighted vessels at $\times 400$ magnification. The mean of the counts for the three most angiogenic and lymphangiogenic areas was recorded. A semiquantitative grading system at low power $(\times 100)$ was also used ( 1 and 2, low and low moderate vascular density; 3 and 4 , high and very high vascular density) (Turner et al. 2000) to assess overall vascular density.

\section{Assessment of VEGF-A, VEGF-C and FGF-2 staining}

Assessment of VEGF-A, VEGF-C and FGF-2 staining was made as reported for other protein immunohistochemical studies (Loda et al. 1997, Porter et al. 1997) with modifications. Four high-power fields $(\times 400$ magnification) from a single representative tissue section, chosen to reflect the area of highest intensity of staining and highest percentage of follicular cells that were positive, were scored and the mean was recorded. The percentage of positive cells was assessed with manual count. Each sample field was assigned a value from 0 to 4 ( 0 , negative; $1,<5 \%$ of the cells with positive staining; 2, between 5 and $50 \%$ of the cells with positive staining; 3 , more than $50 \%$ of the cells with weak staining and 4 , more than $50 \%$ of the cells with strong staining) for VEGF-A, VEGF-C and FGF-2. 


\begin{tabular}{|c|c|c|c|c|c|c|c|c|}
\hline Case & Gender & Age & Histology & $\begin{array}{l}\text { Tumour } \\
\text { size }(\mathrm{mm})\end{array}$ & Multifocal & Metastases & Therapy & Recurrence \\
\hline 1 & $\mathrm{~F}$ & 35 & Papillary ca. & 15 & Yes & $\mathrm{N}(+), \mathrm{M}(0)$ & Total thyrodectomy + ipsilateral lymphadenectomy + I & No \\
\hline 2 & $\mathrm{~F}$ & 56 & Papillary ca. & 29 & No & $\mathrm{N}(+), \mathrm{M}(0)$ & Total thyrodectomy + ipsilateral lymphadenectomy + I & No \\
\hline 3 & $\mathrm{~F}$ & 15 & Papillary ca. & 45 & No & $\mathrm{N}(+), \mathrm{M}(0)$ & Total thyrodectomy + ipsilateral lymphadenectomy + I & No \\
\hline 4 & $\mathrm{~F}$ & 56 & Papillary ca. & 18 & Yes & $\mathrm{N}(+), \mathrm{M}(0)$ & Total thyrodectomy + ipsilateral lymphadenectomy + I & No \\
\hline 5 & M & 42 & Papillary ca. & 55 & No & $\mathrm{N}(+), \mathrm{M}(0)$ & Total thyrodectomy + ipsilateral lymphadenectomy + I & No \\
\hline 6 & $\mathrm{~F}$ & 27 & Papillary ca. & 20 & Yes & $\mathrm{N}(+), \mathrm{M}(0)$ & Total thyrodectomy + ipsi \& contralateral lymphadenectomy + I & No \\
\hline 7 & M & 62 & Papillary ca. & 30 & Yes & $\mathrm{N}(+), \mathrm{M}(0)$ & $\begin{array}{l}\text { Total thyrodectomy + ipsi \& contralateral lymphadenectomy }+ \text { I+ } \\
\text { RT }\end{array}$ & $\begin{array}{l}\text { Yes (neck \& } \\
\text { lungs) }\end{array}$ \\
\hline 8 & $\mathrm{~F}$ & 49 & Papillary ca. & 7 & No & $\mathrm{N}(+), \mathrm{M}(0)$ & Total thyrodectomy + ipsilateral lymphadenectomy + I & No \\
\hline 9 & $\mathrm{~F}$ & 44 & Papillary ca. & 55 & Yes & $\mathrm{N}(+), \mathrm{M}(0)$ & Total thyrodectomy + ipsilateral lymphadenectomy + I & No \\
\hline 10 & M & 28 & Papillary ca. & 25 & Yes & $\mathrm{N}(+), \mathrm{M}(0)$ & Total thyrodectomy +ipsilateral lymphadenectomy + I & No \\
\hline 11 & $\mathrm{~F}$ & 43 & Papillary ca. & 30 & No & $\mathrm{N}(+), \mathrm{M}(0)$ & Total thyrodectomy + ipsilateral lymphadenectomy + I & No \\
\hline 12 & $\mathrm{~F}$ & 45 & Papillary ca. & 30 & No & $\mathrm{N}(+), \mathrm{M}(0)$ & Total thyrodectomy + ipsilateral lymphadenectomy + I & No \\
\hline 13 & M & 36 & Papillary ca. & 35 & No & $\mathrm{N}(+), \mathrm{M}(0)$ & Total thyrodectomy + ipsilateral lymphadenectomy + I & No \\
\hline 14 & $\mathrm{~F}$ & 29 & Papillary ca. & 7 & No & $\mathrm{N}(+), \mathrm{M}(0)$ & Total thyrodectomy + ipsi \& contralateral lymphadenectomy + I & No \\
\hline 15 & $\mathrm{~F}$ & 26 & Papillary ca. & 28 & No & $N(0), M(0)$ & Hemithyroidectomy & No \\
\hline 16 & $\mathrm{~F}$ & 45 & Papillary ca. & 20 & No & $N(0), M(0)$ & Hemithyroidectomy & No \\
\hline 17 & $\mathrm{~F}$ & 33 & Papillary ca. & 30 & No & $N(0), M(0)$ & Hemithyroidectomy & No \\
\hline 18 & $\mathrm{~F}$ & 46 & Papillary ca. & 12 & Yes & $N(0), M(0)$ & Total thyrodectomy + I & No \\
\hline 19 & $\mathrm{~F}$ & 73 & Papillary ca. & 33 & No & $\mathrm{N}(0), \mathrm{M}(0)$ & Total thyrodectomy + ipsilateral lymphadenectomy + I & No \\
\hline 20 & $\mathrm{~F}$ & 74 & Papillary ca. & 70 & Yes & $N(0), M(0)$ & Total thyrodectomy $+\mathrm{I}$ & No \\
\hline 21 & $\mathrm{~F}$ & 15 & Papillary ca. & 40 & No & $N(0), M(0)$ & Total thyrodectomy + I & Yes (lungs) \\
\hline 22 & $\mathrm{~F}$ & 53 & Papillary ca. & 30 & No & $N(0), M(0)$ & Hemithyroidectomy & No \\
\hline 23 & $\mathrm{~F}$ & 28 & Papillary ca. & 50 & No & $N(0), M(0)$ & Total thyrodectomy + ipsi \& contralateral lymphadenectomy +I & No \\
\hline 24 & $\mathrm{~F}$ & 38 & Papillary ca. & 13 & Yes & $N(0), M(0)$ & Total thyrodectomy $+\mathrm{I}$ & No \\
\hline 25 & $\mathrm{~F}$ & 42 & Papillary ca. & 10 & No & $N(0), M(0)$ & Hemithyroidectomy + ipsilateral lymphadenectomy & No \\
\hline 26 & $\mathrm{~F}$ & 66 & Papillary ca. & 39 & No & $N(0), M(0)$ & Hemithyroidectomy + ipsilateral lymphadenectomy & No \\
\hline 27 & M & 46 & Papillary ca. & 12 & Yes & $N(0), M(0)$ & Total thyrodectomy +1 & No \\
\hline 28 & $\mathrm{~F}$ & 41 & Papillary mca. & 10 & No & $N(0), M(0)$ & Total thyrodectomy & No \\
\hline 29 & $\mathrm{~F}$ & 58 & Papillary mca. & 2 & No & $N(0), M(0)$ & Total thyrodectomy & No \\
\hline 30 & $\mathrm{~F}$ & 55 & Papillary mca. & 5 & No & $N(0), M(0)$ & Hemithyroidectomy & No \\
\hline 31 & $\mathrm{~F}$ & 48 & Papillary mca. & 4 & No & $N(0), M(0)$ & Hemithyroidectomy & No \\
\hline 32 & $\mathrm{~F}$ & 45 & Papillary mca. & 10 & No & $N(0), M(0)$ & Hemithyroidectomy & No \\
\hline 33 & $\mathrm{~F}$ & 50 & Papillary mca. & 6 & No & $N(0), M(0)$ & Total thyrodectomy & No \\
\hline 34 & $\mathrm{~F}$ & 45 & Papillary mca. & 8 & No & $N(0), M(0)$ & Hemithyroidectomy & No \\
\hline 35 & $\mathrm{~F}$ & 53 & Papillary mca. & 7 & No & $N(0), M(0)$ & Total thyrodectomy & No \\
\hline 36 & $\mathrm{~F}$ & 61 & Follicular ca. & 20 & No & $\mathrm{N}(0), \mathrm{M}(+$, bone $)$ & Total thyrodectomy $+\mathrm{I}+\mathrm{RT}$ & Yes (bone) \\
\hline 37 & M & 56 & Follicular ca. & 16 & No & $\mathrm{N}(0), \mathrm{M}(+$, bone $)$ & Total thyrodectomy $+\mathrm{I}+\mathrm{RT}$ & No \\
\hline 38 & $\mathrm{~F}$ & 64 & Follicular ca. & 60 & Yes & $\mathrm{N}(0), \mathrm{M}(+$, lung $)$ & Total thyrodectomy + I & No \\
\hline
\end{tabular}




\begin{tabular}{|c|c|c|c|c|c|c|c|c|}
\hline Case & Gender & Age & Histology & $\begin{array}{l}\text { Tumour } \\
\text { size }(\mathrm{mm})\end{array}$ & Multifocal & Metastases & Therapy & Recurrence \\
\hline 39 & $\mathrm{~F}$ & 50 & Follicular ca. & 44 & No & $N(0), M(0)$ & Hemithyroidectomy & No \\
\hline 40 & $\mathrm{~F}$ & 43 & Follicular ca. & 70 & No & $\mathrm{N}(0), \mathrm{M}(0)$ & Total thyrodectomy + I & No \\
\hline 41 & $\mathrm{~F}$ & 28 & Follicular ca. & 40 & No & $N(0), M(0)$ & Hemithyroidectomy & No \\
\hline 42 & $\mathrm{~F}$ & 32 & Follicular ca. & 25 & No & $\mathrm{N}(0), \mathrm{M}(0)$ & Hemithyroidectomy & No \\
\hline 43 & $F$ & 34 & Follicular ca. & 29 & No & $\mathrm{N}(0), \mathrm{M}(0)$ & Hemithyroidectomy & No \\
\hline 44 & $\mathrm{~F}$ & 30 & Follicular ca. & 38 & No & $\mathrm{N}(0), \mathrm{M}(0)$ & Hemithyroidectomy & No \\
\hline 45 & $\mathrm{~F}$ & 45 & Follicular ca. & 32 & No & $\mathrm{N}(0), \mathrm{M}(0)$ & Hemithyroidectomy & No \\
\hline 46 & $\mathrm{~F}$ & 45 & Follicular ca. & 42 & No & $\mathrm{N}(0), \mathrm{M}(0)$ & Hemithyroidectomy & No \\
\hline 47 & M & 81 & Follicular ca. & 45 & No & $\mathrm{N}(0), \mathrm{M}(0)$ & Hemithyroidectomy & No \\
\hline 48 & $\mathrm{~F}$ & 55 & Follicular ca. & 3 & No & $\mathrm{N}(0), \mathrm{M}(0)$ & Total thyrodectomy & No \\
\hline 49 & $\mathrm{~F}$ & 46 & Follicular ca. & 28 & Yes & $\mathrm{N}(0), \mathrm{M}(0)$ & Total thyrodectomy + I & No \\
\hline 50 & $\mathrm{~F}$ & 50 & Follicular ca. & 15 & No & $N(0), M(0)$ & Hemithyroidectomy & No \\
\hline 51 & $\mathrm{~F}$ & 60 & Follicular ca. & 34 & No & $\mathrm{N}(0), \mathrm{M}(0)$ & Total thyrodectomy + I & No \\
\hline 52 & $\mathrm{~F}$ & 40 & Follicular ca. & 35 & Yes & $\mathrm{N}(0), \mathrm{M}(0)$ & Total thyrodectomy + I & No \\
\hline 53 & $F$ & 69 & Follicular ca. & 54 & No & $\mathrm{N}(0), \mathrm{M}(0)$ & Hemithyroidectomy & No \\
\hline 54 & M & 39 & Follicular ca. & 68 & No & $\mathrm{N}(0), \mathrm{M}(0)$ & Hemithyroidectomy & No \\
\hline 55 & $\mathrm{~F}$ & 72 & Follicular ca. & 70 & Yes & $\mathrm{N}(+), \mathrm{M}(0)$ & Total thyrodectomy + ipsilateral lymphadenectomy + I & No \\
\hline 56 & $\mathrm{~F}$ & 51 & Medullary ca. & 25 & No & $\mathrm{N}(+), \mathrm{M}(0)$ & Total thyrodectomy +ipsilateral lymphadenectomy & No \\
\hline 57 & $\mathrm{~F}$ & 62 & Medullary ca. & 15 & Yes & $\mathrm{N}(+), \mathrm{M}(0)$ & Total thyrodectomy + Ipsi \& contralateral lymphadenectomy + RT & No \\
\hline 58 & $\mathrm{~F}$ & 34 & Medullary ca. & 22 & No & $N(+), M(0)$ & Total thyrodectomy + ipsi \& contralateral lymphadenectomy & No \\
\hline 59 & $\mathrm{~F}$ & 41 & Medullary ca. & 95 & Yes & $\mathrm{N}(+), \mathrm{M}(+$, liver $)$ & $\begin{array}{l}\text { Total thyrodectomy + ipsi \& contralateral lymphadenectomy+ } \\
\text { RT + QT }\end{array}$ & No \\
\hline 60 & M & 58 & Medullary ca. & 60 & Yes & $\mathrm{N}(+), \mathrm{M}(+$, bone $)$ & Total thyrodectomy + ipsilateral lymphadenectom & No \\
\hline 61 & $\mathrm{~F}$ & 59 & Medullary ca. & 20 & No & $\mathrm{N}(0), \mathrm{M}(0)$ & Total thyrodectomy & No \\
\hline 62 & $\mathrm{~F}$ & 42 & Medullary ca. & 22 & No & $\mathrm{N}(0), \mathrm{M}(0)$ & Hemithyroidectomy & No \\
\hline 63 & M & 71 & Medullary ca. & 110 & Yes & $\mathrm{N}(+), \mathrm{M}(0)$ & Total thyrodectomy & Yes (neck) \\
\hline
\end{tabular}

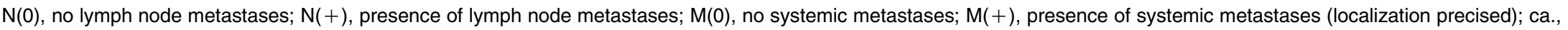
carcinoma; mca., microcarcinoma; I, radioactive iodine; RT, radiotherapy; and QT, chemotherapy. 


\section{Inter- and intra-observer reliability}

Twenty percent of the slides were rescored by a second examiner (H T) and checked for a second time by the main examiner (NGT), both of them blind to the first reading to assess inter- and intra-observer reliability. Inter- and intra-observer reliability was very good with a $100 \%$ agreement for high and low grades for CD34, LYVE-1, VEGF-A, FGF-2 and VEGF-C staining. Assessments of vascular density using mean Chalkley count and grade were highly correlated $(r=0.81$ for CD34 and $r=0.93$ for LYVE-1, $P<0.0001$ for both).

\section{Statistical analysis}

The results were expressed as means \pm s.D. Comparisons between different histological groups were performed by the ANOVA test with additional Bonferroni testing, where significant differences between groups were shown. Differences of $P<0.05$ were considered statistically significant. To measure the strength of the relationship between tumour size and MVD, LVD and expression of VEGF-A, FGF-2 and VEGF-C, the Pearson's correlation coefficient was used. To analyse the association between MVD, LVD and expression of angiogenic and lymphangiogenic factors and tumour behaviour variables (multifocality, regional lymph nodes metastases and distant metastases at the time of thyroidectomy), a logistic regression was performed. Due to the low number of recurrences, association between this and other variables was not possible.

\section{Results}

\section{Microvascular density}

Vascularisation was extremely rich with scores in the Chalkley count ranging between 11.33 and 23.33 out of a maximum of 25. Despite a general high vascular density through all the tissue (Fig. 1a), hot spots were evident in most of the samples in all the histological groups. MVD was higher in normal tissue and samples with PMC than in benign and malignant proliferative lesions. FC samples showed the lowest levels of vascularisation (Fig. 2a). When compared by Bonferroni test FAs and FCs showed a significantly lower MVD (measured with the Chalkley count) than normal tissue, Hy, PC and incidentally found PMC (Fig. 2a).

\section{Lymphatic vascular density}

LYVE-1 staining demonstrated sparse lymphatic vessels with Chalkley scores ranging between 0 and 10. The irregular shaped, thin-walled immunostained lymphatics were clearly distinguished from adjacent blood vessels which did not stain for LYVE-1, were regular in shape, and contained red blood cells (Fig. 1d). Papillary neoplasms (carcinomas and microcarcinomas), MCs and TMNG showed higher LVD. Follicular tumours (adenomas and carcinomas) had the lowest scores (Fig. 2b). When compared using Bonferroni test, FAs showed a significantly lower LVD (measured with the Chalkley count) than PC and incidentally found PMC (Fig. 2b). In benign and malignant follicular neoplasms, lymphatic vessels were localised at the periphery of the lesions adjacent or within the capsule and were usually undetectable within the tumour, while in the other histological groups the distribution was more scattered through the sample. There was no correlation between MVD and LVD assessed by Chalkley count.

\section{Growth factors}

VEGF-A positive staining was present in the thyroid follicular cells (Fig. 3a) and endothelium of blood vessels (Fig. 3b). FGF-2 staining was also localised in both thyroid follicular cells (Fig. 3c and d) and endothelial cells (Fig. 3e). VEGF-C was expressed mainly in the cytoplasm of follicular cells (Fig. 3f), but was occasionally expressed in blood vessels (Fig. 3g). The pattern of subcellular localisation was different for FGF-2, which showed nuclear (Fig. 3c) as well as cytoplasmic localisation (Fig. 3d), compared with VEGF-A and VEGF-C, which accumulated only in the cytoplasm of follicular cells. VEGF-A expression was higher in thyroid carcinomas (papillary, follicular and medullary), with benign proliferative lesions and PMCs showing intermediate levels and normal specimens having the lowest immunopositivity (Fig. 4a). When compared using Bonferroni test, normal samples had significantly lower expression of VEGF-A than Hy, FA, PC, FC and MC. MNG also showed significantly lower expression of this factor than PCs and MCs (Fig. 4a). FGF-2 had a similar pattern of expression with higher scores in thyroid carcinomas and lower scores in normal samples, but the differences with the ANOVA test did not reach statistical significance $(P=0.07)$. There were no correlations between MVD and VEGF-A or FGF-2. PCs showed the highest expression of VEGF-C and normal tissue showed the lowest expression of VEGF-C (Fig. 4b). PCs showed a significantly higher expression of VEGF-C than normal tissue, MNG and FA. Normal tissue expressed significantly lower levels of VEGF-C than Hy and carcinomas (PC, FC and MC) (Fig. 4b). 

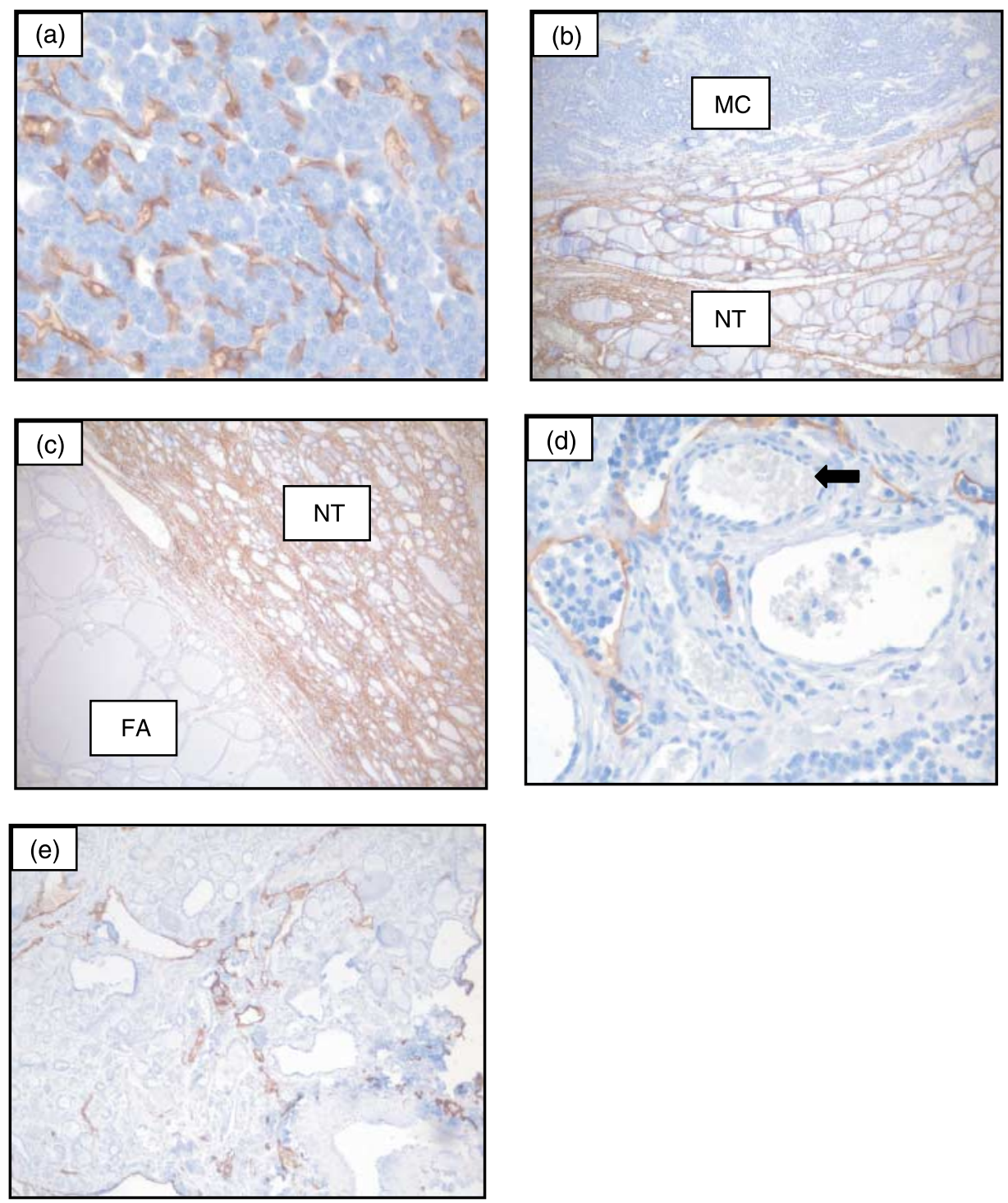

Figure 1 Microvascular density (MVD) and lymphatic vascular density (LVD) in thyroid tissue. (a) CD34 staining in blood vessels in a FA ( $\times 400$ magnification); (b) MVD in a MC compared with MVD in surrounding NT ( $\times 50$ magnification); (c) MVD in a FA compared with MVD in surrounding NT ( $\times 50$ magnification); (d) LYVE-1 staining in lymphatic vessels in contrast to negative staining in blood vessels ( $\times 400$ magnification) in a MC and (e) LVD in a papillary carcinoma (PC) $(\times 50$ magnification). Brown colour indicates positive staining. The black arrow indicates a blood vessel with negative staining. MC, medullary carcinoma; NT, normal tissue; FA, follicular adenoma.

There was a weak correlation between VEGF-C expression and LVD $(r=0.29, P<0.001)$.

\section{Prognostic value of the determination of the angiogenic/lymphangiogenic phenotype in thyroid carcinomas}

Fourteen patients in the PC group had lymphatic metastases at the time of surgery. Ten patients had multifocal disease within the thyroid. No patients had distant metastases at diagnosis. Only two patients had recurrences (lung metastases in both cases at 17 and 18 months of surgery respectively). MVD, LVD and expression of VEGF-A or VEGF-C were not associated with the presence of multifocal disease, regional lymphatic metastases at diagnosis or larger tumour size. FGF-2 expression was negatively associated with multifocality within the thyroid $(P=0.037)$.

Three patients in the FC group presented with distant metastases and only one with local lymphatic metastases at diagnosis. Four patients had multifocal disease. There was only one recurrence in this group (distant). MVD, LVD and expression of VEGF-A, 

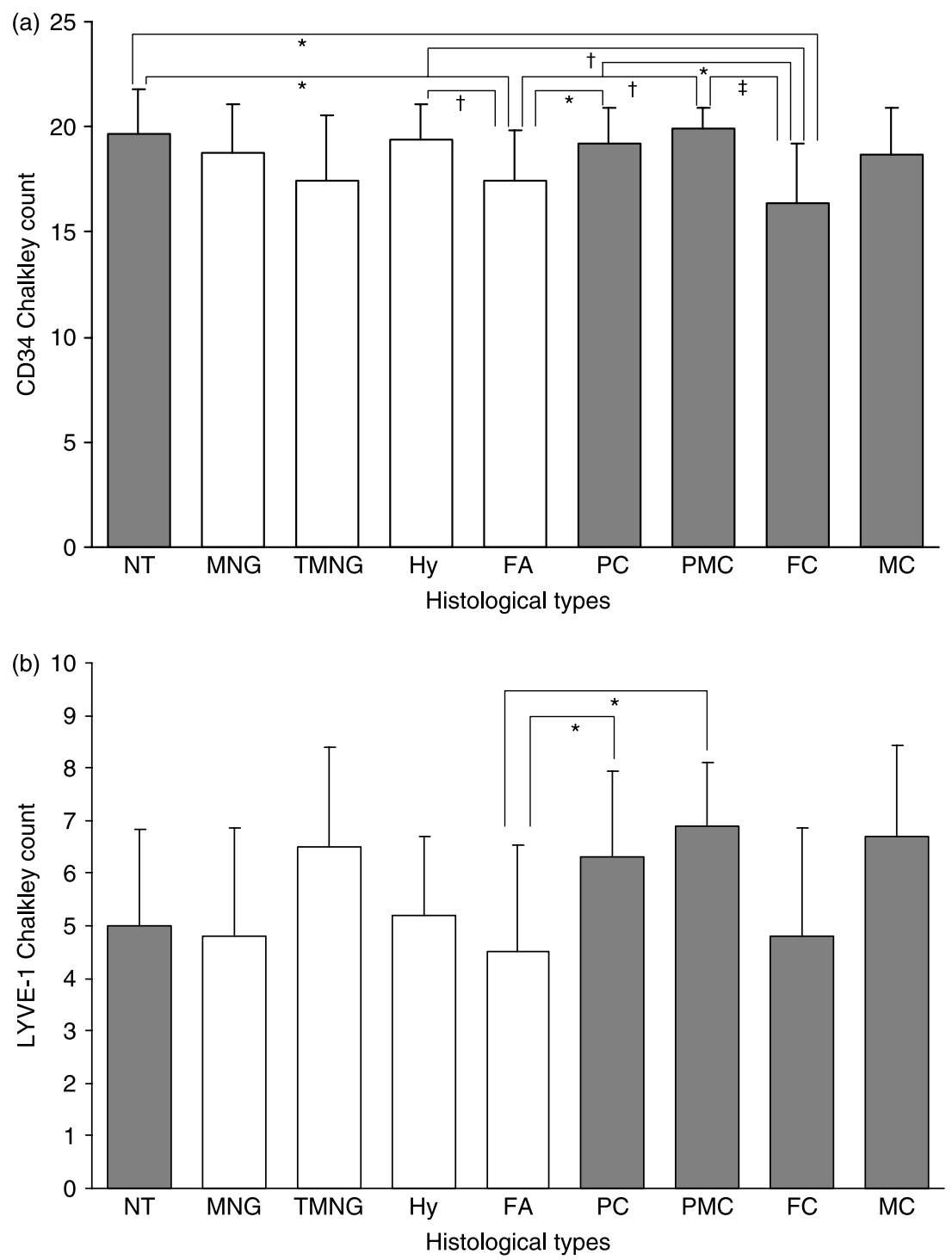

Figure 2 Differences in MVD (a) and LVD (b) assessed by the Chalkley technique between individual groups compared using the Bonferroni test. NT, normal tissue; MNG, multinodular goitre; TMNG, toxic multinodular goitre; Hy, hyperplasia; FA, follicular adenoma; PC, papillary carcinoma; PMC, papillary microcarcinoma incidentally found; FC, follicular carcinoma; MC, medullary carcinoma. ${ }^{\star} P<0.05,{ }^{\dagger} P<0.01,{ }^{\ddagger} P<0.001$.

FGF-2 or VEGF-C were not associated with the presence of multifocal disease, distant metastases at diagnosis or larger tumour size.

Six patients in the MC group (one familial and five sporadic cases) presented with regional lymphatic metastases, two of them also had distant metastases at diagnosis. Four patients had multifocal disease. There was only one case of recurrence (local). VEGFA expression was associated with the presence of lymph node metastases at diagnosis with values above 2.75 predicting perfectly the occurrence of local metastasic disease. Low FGF-2 expression was associated with multifocality within the thyroid with values below 3 predicting the presence of multifocal disease. FGF-2 expression was also inversely correlated with tumour size $(r=-0.66, P<0.001)$.

\section{Discussion}

This is the first study evaluating both angiogenic and lymphangiogenic phenotypes in the same cohort of thyroid proliferative lesions. Our results show a different angiogenic pattern between carcinomas, benign proliferative lesions and normal tissue. Differences were detected by a marker of vascular endothelium (CD34 was found to be higher in normal 

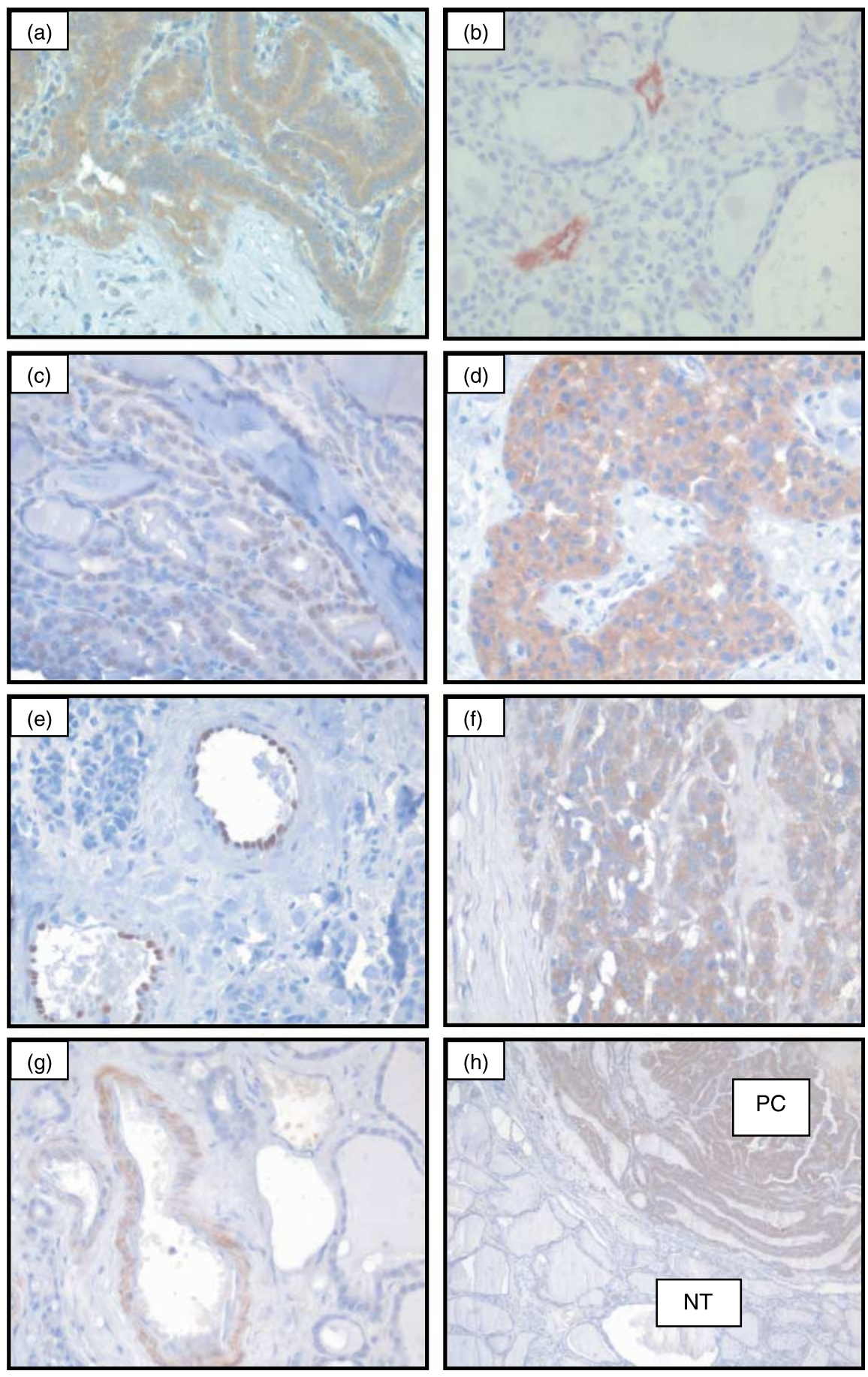

Figure 3 Vascular endothelial growth factor (VEGF-A), fibroblast growth factor-2 (FGF-2) and VEGF-C expression in thyroid tissue. (a) VEGF-A cytoplasmic staining in follicular cells in a PC ( $\times 400$ magnification); (b) VEGF-A staining in blood vessels in a FA ( $\times 400$ magnification); (c) FGF-2 nuclear staining in follicular cells in a PC ( $\times 400$ magnification); (d) FGF-2 cytoplasmic staining in a MC ( $\times 400$ magnification); (e) FGF-2 staining in blood vessels in a MC ( $\times 400$ magnification); (f) VEGF-C cytoplasmic staining in a MC ( $\times 400$ magnification); (g) VEGF-C staining in blood vessels in a MNG $(\times 400$ magnification) and (h) VEGF-C expression in a PC compared with VEGF-C expression in surrounding NT ( $\times 50$ magnification). Brown colour indicates positive staining. PC, papillary carcinoma and NT, normal tissue. 

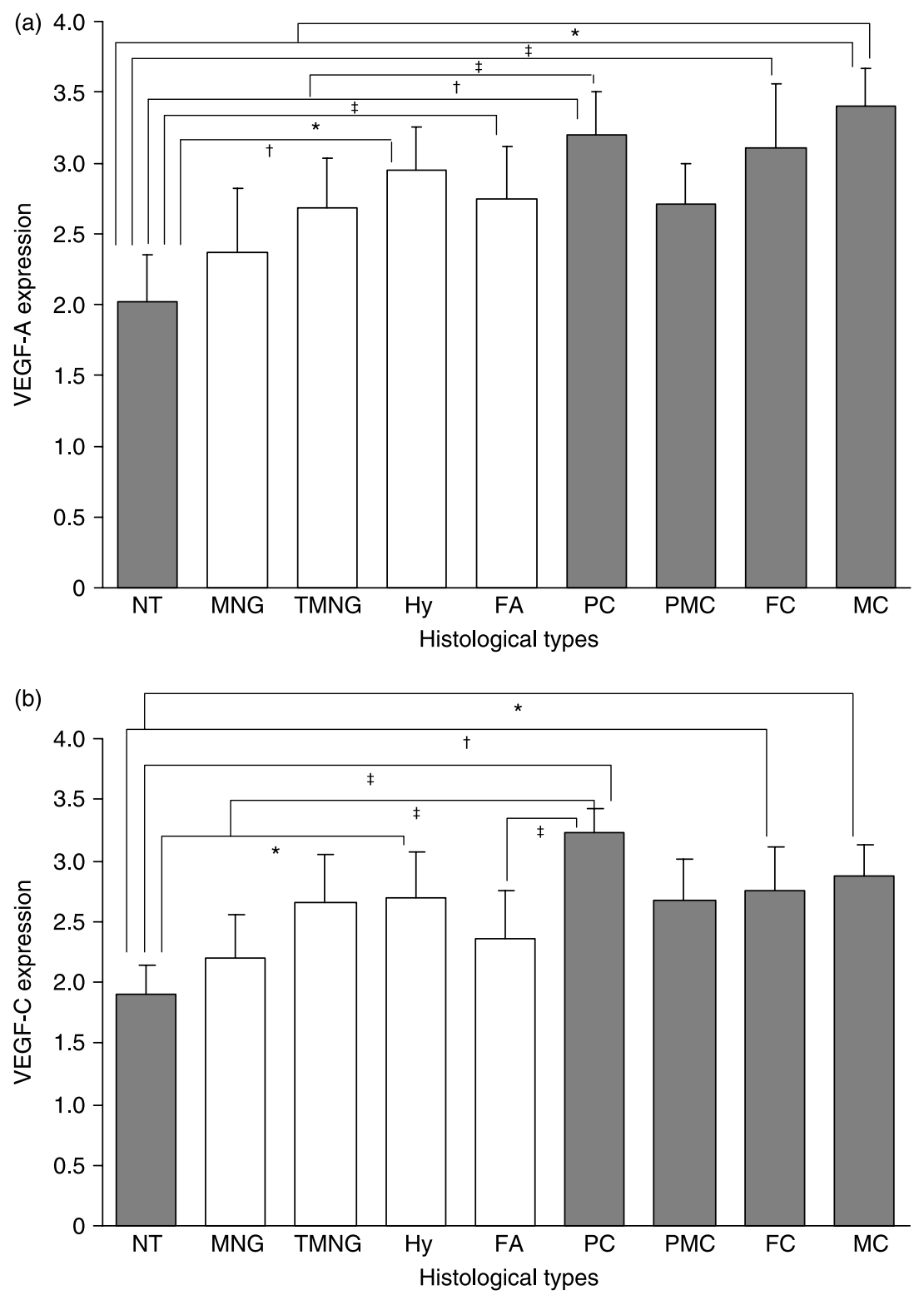

Figure 4 Differences in VEGF-A (a) and VEGF-C (b) expression between individual groups compared by the Bonferroni test. NT, normal tissue; MNG, multinodular goitre; TMNG, toxic multinodular goitre; Hy, hyperplasia; FA, follicular adenoma; PC, papillary carcinoma; PMC, papillary microcarcinoma incidentally found; FC, follicular carcinoma; MC, medullary carcinoma. ${ }^{\star} P<0.05,{ }^{\dagger} P<0.01,{ }^{\ddagger} P<0.001$.

tissue than in some proliferative lesions) and by a marker of angiogenic status (VEGF-A expression was found to be higher in carcinomas than in benign proliferative lesions, and in these benign proliferative lesions, higher than in normal tissue). There were also marked differences in the lymphangiogenic phenotype between PCs prone to lymphatic metastases and FCs prone to extension via the blood stream.

Previous studies suggest that MVD is increased in PC when compared with normal tissue (Akslen \& Livolsi 2000), however, the authors used a different endothelial marker F8, which stains only large vessels but does not label microvessels. In contrast CD34 is a more sensitive and specific marker for use on paraffin sections. The use of different antibodies with varying sensitivities for detection of endothelium may explain the disparate results between the studies. The pattern of higher vascularisation in normal tissue compared with some hyperplastic and neoplastic thyroid specimens is in contrast to a wide variety of tissues, where an increase in the proliferation requires an increase in the vascular supply (Smith-McCune \& Weidner 1994, 
Brem et al. 1978). However, it is a common finding in endocrine tissues such as pituitary (Turner et al. 2000) and adrenal cortex (Bernini et al. 2002). This finding is unexpected regarding vascularisation in Graves' disease where an enlargement in the capillary network has been reported (Nagura et al. 2001). The thyroid gland is vascularised with one of the highest blood flow rates per unit weight of tissue in the body (Cowles et al. 1971). It is possible that when dedifferentiation occurs, thyroid tissue loses the ability to maintain the extremely rich vascularisation of the normal gland showing lower MVD in some proliferative lesions. The lack of statistical difference between normal tissue and PCs and microcarcinomas could be due to the overall low stage of the disease in these groups. No patient at initial presentation had evidence of multifocality or metastases (local or distant) in the PMC group or evidence of distant metastases in the PC group.

The increased expression of VEGF-A, however, suggests that in carcinogenesis an angiogenic switch occurs with subsequent upregulation of pro-angiogenic growth factors in order to produce de novo vascularisation to supply the growing tissue; nevertheless in some cases, the new vascular net is not as rich as that in the normal gland. Alternatively, the low MVD could induce tumour hypoxia and increase VEGF-A expression as a secondary event (Xie et al. 2004), rather than VEGF-A as a primary angiogenic switch. Although we used a standard technique to assess MVD, the anti-CD34 antibody stains all blood endothelial cells, including mature and immature cells, and does not allow the distinction between newly formed vessels, responsible for angiogenesis and pre-existing vessels. In addition, angiogenesis and lymphangiogenesis are dynamic processes, and immunohistochemistry offers only a static view of the remodelling vasculature.

The upregulation in VEGF-A expression in thyroid proliferative lesions, especially carcinomas, is in agreement with previous in vitro and in vivo studies. In vitro human thyroid follicular cells grown in culture can synthesise and secrete VEGF-A, and the basal level of mRNA expression can be increased by factors signalling through the cAMP and protein kinase $\mathrm{C}$ pathways, including TSH, dibutyryl cAMP and Graves' disease serum (Sato et al. 1995). In our cohort, all the patients were euthyroid at the time of surgery; however, we cannot eliminate the possibility that in patients with Graves' disease, the TSH levels were deranged at some point pre-operatively, and this may have had some effect on growth factor expression levels. In vivo, using a model of induced goitre in thiouracil-fed rats, VEGF receptors 1 and 2 mRNA expression increases during goitre formation and this occurs subsequent to the increase in plasma of TSH, and in parallel with thyroid capillary proliferation. In Graves' disease there is enhanced expression of mRNA for VEGF-A in addition to VEGF receptors 1 and 2 (Viglietto et al. 1997) as measured by northern blot hybridisation. In our cohort, the Hy group showed a significantly higher expression of VEGF-A than normal tissue. VEGF-A also seems to be important in thyroid tumours. Immunostaining of thyroid tumours shows co-localisation of increased Ki-67 (to show cell kinetics of thyrocytes) and VEGF-A staining (Klein et al. 1999), and this may be because areas of tumour with rapid cell division are associated with increased VEGF-A secretion to promote the formation of a de novo vascular net to supply the growing tissue. The same study also showed greater immunostaining for VEGF-A in tumours compared with normal tissue and thyroiditis, and more specifically for those with a metastatic spread. Regarding the prognostic value of VEGF-A expression in differentiated thyroid carcinomas, the available studies have shown conflicting results. Bunone et al. (1999) showed a significant association between tumour size and high levels of VEGF-A expression. Fenton et al. (2000) also found a correlation between the expression of VEGF-A and the size of tumour in 42 children and young adults with papillary thyroid carcinoma. In further studies performed in elderly patients, such a correlation was not found, but they showed that VEGF-A immunostaining score was an independent marker for lymph node or systematic metastases occurrence at the time of thyroidectomy (Klein et al. 2001, Kilicarslan et al. 2003) and in a large cohort of 96 patients, it was strongly associated with local and distant recurrence and decrease in disease-free survival (Lennard et al. 2001). In contrast, Huang et al. (2001) showed that immunohistochemical expression of VEGF-A did not correlate with tumour size, extent of invasion, or scores on the AGES system (patient age, tumour size, histologic grade, tumour extent, distant metastases) or the MACIS system (metastases, age, completeness of resection, invasion, tumour size) in the analysis of 76 PCs. The authors concluded, in agreement with our results, that determination of the angiogenic phenotype may have limited prognostic value for patients with PC. In our series, VEGF-A was only associated with the presence of local lymphatic metastases at the time of thyroidectomy in $\mathrm{MC}$, but not in differentiated epithelial carcinomas of the thyroid. These studies have employed different techniques to quantify VEGFA expression, and have used different antibodies 
reactive to VEGF-A, which may explain some of the conflicting results.

We observed a trend to a higher expression of FGF-2 in carcinomas compared with benign proliferative lesions, and in benign lesions compared with normal tissue. These results support previous studies where expression of FGF-2 was increased in both benign and malignant neoplasia compared with NT tissue (Eggo et al. 1995). In addition, when malignant tumours were compared with thyroid benign diseases and normal controls, FGF-2 expression was more frequently detected in malignant neoplasia, with anaplastic carcinomas showing the strongest immunoreactivity (Shingu et al. 1994), adding support to a relationship between FGF-2 expression and tumour behaviour. Recently, a potential prognostic value for FGF-2 gene expression in differentiated carcinomas of the thyroid has been suggested (Boelaert et al. 2003). Our data on protein expression do not confirm these results; furthermore, FGF-2 expression was negatively associated with multifocal disease in PCs and MCs and inversely correlated with tumour size in MCs. It might be that FGF-2 plays a role in the new development of thyroid cancer being upregulated mainly during the early stages of carcinogenesis. Therefore, according to our results determination of VEGF-A and FGF-2 expression in thyroid carcinomas has a very limited prognostic value.

The development of intratumour lymphatics in papillary thyroid carcinoma, assessed by immunostaining for the novel lymphatic endothelial hyaluronan receptor LYVE-1, has been reported previously (Hall et al. 2003). However, in contrast to our data, the presence of intratumour lymphatics was significantly associated with the presence of nodal metastases at presentation. To our knowledge, there are no previous studies analysing the development of lymphatic vessels in other histological types of thyroid carcinoma such as FC and MC.

Previous studies have documented an increased expression of VEGF-C mRNA in PCs compared with FCs (Bunone et al. 1999, Fellmer et al. 1999). However, the upregulation of VEGF-C expression in other thyroid carcinomas prone to lymph node metastases, such as MC is controversial. Bunone et al. (1999) showed that patients with thyroid carcinomas which frequently occur with nodal involvement (papillary, medullary and undifferentiated) had upregulation of VEGF-C mRNA levels and significantly higher protein expression of VEGF-C than those with tumours without nodal involvement (FAs and FCs). In addition, VEGF-C mRNA was upregulated prominently in node-positive tumours.
In contrast, Hung et al. (2003) found an increased expression of VEGF-C mRNA in papillary thyroid cancer, but not in MCs. The prognostic value of VEGF$\mathrm{C}$ expression has also been debated. The presence of metastatic lymph nodes had been shown to be positively correlated with the expression of VEGF-C in the primary tumour (Tanaka et al. 2002, Yu et al. 2005). However, these results could not be confirmed by Hung et al. (2003) who, in agreement with our data, did not find any significant differences in VEGF-C expression in papillary thyroid cancers from patients, who had or did not have cervical node metastases at thyroidectomy. We have shown an increased LVD and upregulation of VEGF-C expression in PCs. This could represent an important mechanism underlying the differences in metastasic behaviour between papillary and follicular thyroid cancer. It is known that the level of VEGF-C mRNA is upregulated by various factors including IL-1 $\alpha$ (Ristimaki et al. 1998). In view of the fact that PC but not FC produces IL-1 (Kayser et al. 1995), then this cytokine may be partly responsible for the difference in the degree of VEGF-C mRNA expression between these two types of thyroid carcinoma. Surprisingly, we found only a weak correlation between LVD and VEGF-C expression. Taken together, our results show that lymphangiogenesis is a complex process and that the expression of VEGF-C is not the only mechanism in lymphangiogenesis and lymph node metastases. Other factors are likely to be involved.

In conclusion, in contrast to common cancers, but similar to other endocrine neoplasms such as pituitary and adrenal cortex tumours, angiogenesis is reduced in some thyroid proliferative lesions compared with normal tissue. VEGF-A expression is upregulated in thyroid cancers compared with normal tissue. Lymphangiogenesis and VEGF-C expression are increased in PCs prone to lymphatic metastases and this could be an important mechanism for the different metastasic behaviour between these and FCs. Despite a higher expression of some angiogenic and lymphangiogenic growth factors in thyroid carcinomas, the determination of the angiogenic and lymphangiogenic phenotypes in thyroid neoplasms has a very limited prognostic value.

\section{Acknowledgements}

We gratefully acknowledge Dr Helen Turley for the donation of CD34 and VEGF-A antibodies, Dr David Jackson for the donation of LYVE-1 antibody and Dr Brian Shine and Dr Miguel Angel Rubio for statistical advice. The authors declare that there is no conflict of 
interest that would prejudice the impartiality of this scientific work.

This work was supported by The Oxford Radcliffe Hospital Charitable Fund (Grant 1057295) and the Novo Nordisk Foundation.

\section{References}

Akslen LA \& Livolsi VA 2000 Increased angiogenesis in papillary thyroid carcinoma but lack of prognostic importance. Human Pathology 31 439-342.

Bernini GP, Moretti A, Bonadio AG, Menicagli M, Viacava P, Naccarato AG, Iacconi P, Miccoli P \& Salvetti A 2002 Angiogenesis in human normal and pathologic adrenal cortex. Journal of Clinical Endocrinology and Metabolism 87 4961-4965.

Boelaert K, McCabe CJ, Tannahill LA, Gittoes NJL, Holder RL, Watkinson JC, Bradwell AR, Sheppard MC \& Franklyn JA 2003 Pituitary tumor transforming gene and fibroblast growth factor-2 expression: potential prognostic indicators in differentiated thyroid cancer. Journal of Clinical Endocrinology and Metabolism 88 2341-2347.

Brem SS, Gullino PM \& Medina D 1978 Angiogenesis as a marker of preneoplastic lesions of the human breast. Cancer 41 239-244.

Bunone G, Vigneri P, Mariani L, Buto S, Collini P, Pilotti S, Pierotti MA \& Bongarzone I 1999 Expression of angiogenesis stimulators and inhibitors in human thyroid tumors and correlation with clinical pathological features. American Journal of Pathology 155 1967-1976.

Cowles AL, Borgstedt HH \& Gillies AJ 1971 Tissue weights and rates of blood flow in man for the prediction of anesthetic uptake and distribution. Anesthesiology 35 523-526.

Eggo MC, Hopkins JM, Franklyn JA, Johnson GD, Sanders DS \& Sheppard MC 1995 Expression of fibroblast growth factors in thyroid cancer. Journal of Clinical Endocrinology and Metabolism 80 1006-1011.

Esser S, Wolburg K, Wolburg H, Breier G, Kurzchalia T \& Risau W 1998 Vascular endothelial growth factor induces endothelial fenestrations in vitro. Journal of Cell Biology 140 947-959.

Fellmer PT, Sato K, Tanaka R, Okamoto T, Kato Y, Kobayashi M, Shibuya M \& Obara T 1999 Vascular endothelial growth factor-C gene expression in papillary and follicular thyroid carcinomas. Surgery $\mathbf{1 2 6}$ 1056-1062.

Fenton C, Patel A, Dinauer C, Robie DK, Tuttle RM \& Francis GL 2000 The expression of vascular endothelial growth factor and the type 1 vascular endothelial growth factor receptor correlate with the size of papillary thyroid carcinoma in children and young adults. Thyroid $\mathbf{1 0}$ 349-357.

Ferrara N \& Bunting S 1996 Vascular endothelial growth factor, a specific regulator of angiogenesis. Current Opinion in Nephrology and Hypertension 5 35-44.
Folkman J 1989 What is the evidence that tumors are angiogenesis dependent? Journal of the National Cancer Institute 82 4-6.

Fox SB, Leek RD, Weekes MP, Whitehouse RM, Gatter KC \& Harris AL 1995 Quantitation and prognostic value of breast cancer angiogenesis: comparison of microvessel density, Chalkley count, and computer image analysis. Journal of Patholology 177 275-283.

Hall FT, Freeman JL, Asa SL, Jackson DG \& Beasley NJ 2003 Intratumoral lymphatics and lymph node metastases in papillary thyroid carcinoma. Archives of Otolaryngology, Head \& Neck Surgery 129 716-719.

Huang SM, Lee JC, Wu TJ \& Chow NH 2001 Clinical relevance of vascular endothelial growth factor for thyroid neoplasms. World Journal of Surgery 25 302-306.

Hung CJ, Ginzinger DG, Zarnegar R, Kanauchi H, Wong MG, Kebebew E, Clark OH \& Duh QY 2003 Expression of Vascular endothelial growth factor-C in benign and malignant thyroid tumors. Journal of Clinical Endocrinology and Metabolism 88 3694-3699.

Jeltsch M, Kaipainen A, Joukov V, Meng X, Lakso M, Rauvala H, Swartz M, Fukumura D, Jain RK \& Alitalo K 1997 Hyperplasia of lymphatic vessels in VEGF-C transgenic mice. Science 276 1423-1425.

Kayser L, Broholm H, Francis D, Perrild H, Olsen BE, Bendtzen K \& Hoyer PE 1995 Immunocytochemical localisation of interleukin-1 alpha and interleukin- 6 in thyroid tissues from patients with neoplastic or autoimmune thyroid disorders. Autoimmunity 20 75-82.

Kilicarslan AB, Ogus M, Arici C, Pestereli HE, Cakir \& Karpuzoglu G 2003 Clinical importance of vascular endothelial growth factor (VEGF) for papillary thyroid carcinomas. APMIS 111 439-443.

Kim DS, McCabe CJ, Buchanan MA \& Watkinson JC 2003 Oncogenes in thyroid cancer. Clinical Otolaryngology and Allied Sciences 28 386-395.

Klein M, Picard E, Vignaud JM, Marie B, Bresler L, Toussaint B, Weryha G, Duprez A \& Leclere J 1999 Vascular endothelial growth factor gene and protein: strong expression in thyroiditis and thyroid carcinoma. Journal of Endocrinology 161 41-49.

Klein M, Vignaud JM, Hennequin V, Toussaint B, Bresler L, Plenat F, Leclere J, Duprez A \& Weryha G 2001 Increased expression of the vascular endothelial growth factor is a pejorative prognosis marker in papillary thyroid carcinoma. Journal of Clinical Endocrinology and Metabolism 86 656-658.

Lennard CM, Patel A, Wilson J, Reinhardt B, Tuman C, Fenton C, Blair E, Francis GL \& Tuttle RM 2001 Intensity of vascular endothelial growth factor expression is associated with increased risk of recurrence and decreased disease-free survival in papillary thyroid cancer. Surgery 129 552-558.

Loda M, Cukor B, Tam SW, Lavin P, Fiorentino M, Draetta GF, Jessup JM \& Pagano M 1997 Increased 
proteasome-dependent degradation of the cyclindependent kinase inhibitor p27 in aggressive colorectal cancer. Nature Medicine 3 231-234.

Nagura S, Katoh R, Miyagi E, Shibuya M \& Kawaoi A 2001 Expression of vascular endothelial growth factor (VEGF) and VEGF receptor-1 (Flt-1) in Graves disease possibly correlated with increased vascular density. Human Pathology 32 10-17.

Nisato RE, Tille JC \& Pepper MS 2003 Lymphangiogenesis and tumor metastasis. Thrombosis and Haemostasis $\mathbf{9 0}$ 591-597.

Oh SJ, Jeltsch MM, Birkenhager R, McCarthy JE, Weich HA, Christ B, Alitalo K \& Wilting J 1997 VEGF and VEGF-C: specific induction of angiogenesis and lymphangiogenesis in the differentiated avian chorioallantoic membrane. Developmental Biology 188 96-109.

Porter PL, Malone KE, Heagerty PJ, Alexander GM, Gatti LA, Firpo EJ, Daling JR \& Roberts JM 1997 Expression of cellcycle regulators $\mathrm{p} 27 / \mathrm{Kip} 1$ and cyclin $\mathrm{E}$, alone and in combination, correlate with survival in young breast cancer patients. Nature Medicine 3 222-225.

Ristimaki A, Kirsi N, Enholm B, Joukov V \& Alitalo K 1998 Proinflammatory cytokines regulate expression of the lymphatic endothelial mitogen vascular endothelial growth factor. Journal of Biological Chemistry 273 8413-8418.

Rodriguez JM, Pinero A, Ortiz S, Moreno A, Sola J, Soria T, Robles R \& Parrilla P 2000 Clinical and histological differences in anaplastic thyroid carcinoma. European Journal of Surgery 166 34-38.

Sato K, Yamazaki K, Shizume K, Kanaji Y, Obara T, Ohsumi K, Demura H, Yamaguchi S \& Shibuya M 1995 Stimulation by thyroid-stimulating hormone and Grave's immunoglobulin G of vascular endothelial growth factor mRNA expression in human thyroid follicles in vitro and flt mRNA expression in the rat thyroid in vivo. Journal of Clinical Invesigation 96 1295-1302.

Scollo C, Baudin E, Travagli JP, Caillou B, Bellon N, Leboulleux S \& Schlumberger M 2003 Rationale for central and bilateral lymph node dissection in sporadic and hereditary medullary thyroid cancer. Journal of Clinical Endocrinology and Metabolism 88 2070-2075.

Shingu K, Sugenoya A, Itoh N \& Kato R 1994 Expression of basic fibroblast growth factor in thyroid disorders. World Journal of Surgery 18 500-505.

Skobe M, Hawighorst T, Jackson DG, Prevo R, Janes L, Velasco P, Riccardi L, Alitalo K, Clafey K \& Detmar M 2001 Induction of tumor lymphangiogenesis by VEGF-C promotes breast cancer metastasis. Nature Medicine 7 192-198.

Smith-McCune KK \& Weidner N 1994 Demonstration and characterization of the angiogenic properties of cervical dysplasia. Cancer Research 54 800-804.
Stewart M, Talks K, Leek R, Turley H, Pezzella F, Harris A \& Gatter K 2002 Expression of angiogenic factors and hypoxia inducible factors HIF 1, HIF 2 and CA IX in non-Hodgkin's lymphoma. Histopathology 40 253-260.

Tanaka K, Kurebayashi J, Sonoo H, Otsuki T, Yamamoto Y, Ohkubo S, Yamamoto S \& Shimozuma K 2002 Expression of vascular endothelial growth factor family messenger RNA in diseased thyroid tissues. Surgery Today 32 761-768.

Trojan L, Michel MS, Rensch F, Jackson DG, Alken P \& Grobholz R 2004 Lymph and blood vessel architecture in benign and malignant prostatic tissue: lack of lymphangiogenesis in prostate carcinoma assessed with novel lymphatic marker lymphatic vessel endothelial hyaluronan receptor (LYVE-1). Journal of Urology 172 103-107.

Turley H, Scott PA, Watts VM, Bicknell R, Harris AL \& Gatter KC 1998 Expression of VEGF in routinely fixed material using a new monoclonal antibody VG1.

Journal of Pathology 186 313-318.

Turner HE, Nagy Z, Gatter KC, Esiri MM, Harris AL \& Wass JAH 2000 Angiogenesis in pituitary adenomas and the normal pituitary gland. Journal of Clinical Endocrinology and Metabolism 85 1159-1162.

Viglietto G, Romano A, Manzo G, Chiappetta G, Paoletti I, Califano D, Galati MG, Mauriello V, Bruni P, Lago CT et al. 1997 Upregulation of the angiogenic factors PlGF, VEGF and their receptors (Flt-1, Flk-1/KDR) by TSH in cultured thyrocytes and in the thyroid gland of thiouracilfed rats suggest a TSH-dependent paracrine mechanism for goiter hypervascularization. Oncogene $\mathbf{1 5}$ 2687-2698.

Vlodavsky I, Fridman R, Sullivan R, Sasse J \& Klagsbrun M 1987 Aortic endothelial cells synthesize basic fibroblast growth factor which remains cell associated and platelet-derived growth factor-like protein which is secreted. Journal of Cellular Physiology 131 402-408.

Yancopoulos GD, Davis S, Gale NW, Rudge JS, Wiegand SJ \& Holash J 2000 Vascular-specific growth factors and blood vessel formation. Nature $\mathbf{4 0 7}$ 242-248.

Yu XM, Lo CY, Chan WF, Lam KY, Leung P \& Luk JM 2005 Increased expression of vascular endothelial growth factor $\mathrm{C}$ in papillary thyroid carcinoma correlates with cervical lymph node metastases. Clinical Cancer Research 11 8063-8069.

Xie K, Wei D, Shi Q \& Huang S 2004 Constitutive and inducible expression and regulation of vascular endothelial growth factor. Cytokine \& Growth Factor Reviews 15 297-324. 